\title{
Are the functional movement analysis scores of handball players related to athletic parameters?
}

\author{
Emre Serdar Atalay 1, , Devrim Tarakci², Candan Algun ${ }^{3}$ \\ 'Department of Physical Therapy and Rehabilitation, University of Health Sciences, Istanbul, Turkey \\ ${ }^{2}$ Department of Occupational Therapy, Istanbul Medipol University, Istanbul, Turkey \\ ${ }^{3}$ Department of Physical Therapy and Rehabilitation, Istanbul Medipol University, Istanbul, Turkey
}

Handball is a popular sport in many countries. There is lack of knowledge about handball athlete's functional movement capacity. The aim of this study is to investigate the Functional Movement Screen (FMS) scores, to evaluate the injury risks of handball athletes and to determine its relationship with athletic performance. A total of 51 professional handball players were included in this study. The sport-specific features and demographic data were recorded. The functional movement analysis was performed, agility and balance and force were evaluated. 37 were females and 14 were males. The mean age $21.00 \pm 4.50$ years (range, 16-35 years). The mean FMS scores of handball athletes were $12.86 \pm 2.57$. In addition, asymmetries were found between the left and right side FMS scores. There was a statistically significant poor correla- tion between the FMS and agility $(r=0.292, P=0.038)$ and balance (right: $r=0.224, P=0.024$; left: $r=0.228, P=0.022$ ). Handball is a risky sport for injuries; therefore, athletes, coaches, and medical staff should recognize about the removal of functional deficiency before performance training. The FMS is a useful and cost-effective approach to identify these deficiencies. It is necessary not only to prevent injuries, but also to improve performance. These tests must be done before every season and, then, corrective, medical, or conservative approaches may be applied to athletes before performance training. (Clinical Trial ID: NCT03468569)

Keywords: Handball, Movement, Agility, Balance, Force

\section{INTRODUCTION}

Handball is one of the most popular team sports in the world in which two teams of players pass a ball using their hands to throw it into the goal of the other team. This game requires being physically fit and talented, and it also requires agility and strategic game play. According to the International Olympic Committee, handball is an Olympic sport with a high risk of injury (Karcher and Buchheit, 2014). This game is characterized by high tempo, massive movement changes, jumps that end with hard strikes, frequent contact between athletes, and repetitive knee and shoulder injuries (Bencke et al., 2013). Before rehabilitation, therefore, strength and fitness programs are applied to an athlete and possible deficiencies in the biomechanical array are attempted to be re- vealed, by examining the motion patterns, but not a region alone.

In handball, functional movement patterns are used as in other sports. Prevention of injuries is only possible with a detailed and holistic analysis (Shojaedin et al., 2014). Currently, the most commonly used method for this analysis is the Functional Movement Screen (FMS), which is used to analyze the movement patterns and to show appropriate approaches, to increase the athletic performance of the athletes, and to protect them from injuries (Cook et al., 2006a).

The FMS evaluates the ability to move in three motion planes (Chorba et al., 2010). It includes an assessment of qualitative and quantitative information about the specialized movements involved in the functional activities. These tests provide information about the athlete's pain, muscle strength and power, lower ex-
${ }^{*}$ Corresponding author: Emre Serdar Atalay (i) https://orcid.org/0000-0002-8249-8628 Department of Physical Therapy and Rehabilitation, Faculty of Health Sciences, University of Health Sciences, Selimiye Mah. Tibbiye Cad. No:38 34668 Üsküdar, Istanbul, Turkey

Tel: +90-2163463636 (ext: 2615), Fax: +90-2163463640

E-mail: emreserdar.atalay@sbu.edu.tr

Received: August 2, 2018 / Accepted: September 29, 2018
This is an Open Access article distributed under the terms of the Creative Commons Attribution Non-Commercial License (http://creativecommons.org/licenses/by-nc/4.0/) which permits unrestricted non-commercial use, distribution, and reproduction in any medium, provided the original work is properly cited. 
tremity joint stability in multiple motion planes, endurance, muscle flexibility, balance, proprioception, speed, agility, and aerobic and anaerobic fitness (Narducci et al., 2011).

There are some studies that show relation of FMS score with injury risk (Chorba et al., 2010, Garrison et al., 2015; Kiesel et al., 2007) To prevent injuries, placement of the screening system in the handball sport is critical in terms of developing sports, increasing team success, and reducing financial burden. In the literature, there are several studies using FMS in different sports fields. However, there is no study showing the FMS scores of handball athletes. In the present study, therefore, we aimed to determine the scores of the FMS of handball athletes and to investigate the relationship between these scores and athletic performance parameters.

\section{MATERIALS AND METHODS}

\section{Design and subjects}

The study included a total of 51 healthy handball athletes aged between 18 and 35 years from four different professional teams between July 2016 and September 2016. Physical characteristics of the participants are shown in Table 1. A written informed consent was obtained from each participant. The study was approved by the Istanbul Medipol University Ethics Committee and conducted in accordance with the principles of the Declaration of Helsinki.

Inclusion criteria are; being licensed super league or 1st division handball player. Not to have an operation related to musculoskeletal system last 6 months. Exclusion criteria are; feeling pain or discomfort during tests.

All participants underwent initial examination at the beginning of the season. The handball athletes were analyzed by the following evaluation station established on the track they were training on: (a) Station 1-Y balance test, (b) Station 2-FMS test, (c) Station 3-Vertical jump test, and (d) Station 4-Illinois agility test.

Before starting each test, the athletes warmed up approximately

Table 1. Physical characteristics of the participants $(n=51)$

\begin{tabular}{lc}
\hline Characteristic & Value \\
\hline Sex, female:male & $37(72.5): 14(27.5)$ \\
Age $(\mathrm{yr})$ & $21.00 \pm 4.50$ \\
Height $(\mathrm{m})$ & $1.75 \pm 0.09$ \\
Weight $(\mathrm{kg})$ & $68.10 \pm 12.57$ \\
Body mass index $\left(\mathrm{kg} / \mathrm{m}^{2}\right)$ & $22.10 \pm 2.18$
\end{tabular}

Values are presented as number (\%) or mean \pm standard deviation.
10 min. between each station and 10-min breaks were allowed. Demographic characteristics of the athletes, sports and injury histories, and monthly training and match times were recorded.

\section{Methods}

\section{$Y$ balance test}

The $\mathrm{Y}$ balance, defined as the first station, was applied using the tape measures affixed in the form of an inverted $Y$ letter according to the posture of the participant. The remaining leg was the side to be tested, and all participants were asked to extend their legs anteriorly, posterolaterally, and posteromedially and to return to the baseline position with full balance. The final point where the foot stretched was recorded in $\mathrm{cm}$. The test was administered bilaterally (Plisky et al., 2009; Wischmeyer et al., 2016).

\section{Functional movement analysis}

The second station (FMS), is a scanning system which include seven steps (i.e., deep squat, hurdle step, in-line lunge, shoulder mobility, active leg raise, trunk stability push-up, and rotary stability) and clearing tests (i.e., for shoulder mobility, trunk stability push up and rotary stability) (Cook et al., 2006a; Cook et al., 2006b). The FMS test kit is used to perform the test. This kit consists of the main test piece, two auxiliary fixed measuring sticks, an elastic rope, and a moving measuring stick. About $15 \mathrm{~m}^{2}$ of space is sufficient to perform the test. The test is carried out by the practitioner watching the tests during a maximum of three repetitions and giving a score of $0-3$ according to this observation (Cook et al., 2006a). If the participant feels pain during test, 0 point is given although he/she manages to perform the test. Scoring was done by a physiotherapist who had received an FMS course certificate. In our study, the same FMS protocol was used.

\section{Agility evaluation}

The Illinois Agility Test was used in the third station. In this test, agility of a player was measured at $9.2 \times 7.2-\mathrm{m}$ field. The completion time of the prepared course was recorded with a stopwatch. The athlete was given three trials by giving rest breaks and the best score was recorded.

\section{Vertical jump test}

The vertical jump test was used in the fourth station. In this test, the face of the participant was rotated to the side of the wall, and the value was recorded on the slice fixed to the wall from the point of the fingertip. The participant, then, jumped as high as possible, and the height he/she leaned over was repeatedly read 
through the tape measure. The difference between the initial and the final value was calculated as the jump height. Three trials were performed, and the highest value was recorded (Carlock et al., 2004; Singh et al., 2016).

\section{Statistical analysis}

Statistical analysis was performed using the IBM SPSS Statistics ver. 25.0 (IBM Co., Armonk, NY, USA). Descriptive data were expressed in mean \pm standard deviation, median (range), number, and percentage. One-sample Kolmogorov-Smirnov test was used to analyze the normality of the distribution of data. The distribution of the data was found to be normal and Pearson correlation analysis was used. A $P$-value of $<0.05$ was considered statistically significant.

\section{RESULTS}

Of a total of 51 professional handball players included in this study, 37 were females and 14 were males. The mean age $21.00 \pm$ 4.50 years (range, 16-35 years). Demographic characteristics and sports and injury histories of the athletes are shown in Table 1. The monthly training and match times are shown in Table 2. The player positions are shown in Table 3 .

In the last year, the mean retaining time from training or play due to an injury was $30.56 \pm 58.27$ days per athlete. The number of injuries per athlete was found to be 115.81 per 1,000 match hours and 9.93 per 1,000 training hours.

Furthermore, the number of injuries of the athletes in the last

Table 2. Sport-related statistics

\begin{tabular}{lr}
\hline Variable & Mean \pm SD \\
\hline Sport age $(y r)$ & $10.25 \pm 4.86$ \\
Monthly training hour & $53.92 \pm 12.3$ \\
Monthly match play hour & $4.62 \pm 1.46$ \\
\hline
\end{tabular}

$\mathrm{SD}$, standard deviation.

Table 3. Playing positions of athletes

\begin{tabular}{lc}
\hline Variable & No. $(\%)$ \\
\hline Left wing & $13(25.49)$ \\
Middle playmaker & $11(21.56)$ \\
Goalkeeper & $8(16.68)$ \\
Pivot & $7(13.72)$ \\
Right wing & $5(9.80)$ \\
Left playmaker & $5(9.80)$ \\
Right playmaker & $2(3.92)$
\end{tabular}

one year and FMS scores were not found correlated $(r=-0,170$, $P=0,234)$. There was no relationship between age of athletes and FMS total scores $(r=-0,049, P=0,733)$. The relationship between the Illinois Agility Test results and FMS total scores was statistically significant $(r=-0.292, P=0.038)$. The relationships between FMS scores and other parameters of athletes are shown in Table 4.

However, there was no relationship between the FMS scores and $\mathrm{Y}$ balance test scores on the right posteromedial and left posterolateral. Nonetheless, we found a relationship between the other FMS parameters and $\mathrm{Y}$ balance test.

A total of 28 athletes scored below 14 points, 23 athletes scored over 14 points in FM scoring. According to the asymmetry evaluation, 35 athletes had asymmetry, while 16 athletes did not according to the FMS's right and left side. FMS scores of the athletes

Table 4. The relationship between functional movement screen scores and other parameters of athletes

\begin{tabular}{lcc}
\hline Variable & $r$ & $P$-value \\
\hline Injury count & -0.170 & 0.234 \\
Y balance test right anterior & $0.283^{*}$ & 0.004 \\
Y balance test right posterolateral & $0.198^{*}$ & 0.048 \\
Y balance test right posteromedial & 0.145 & 0.149 \\
Y balance test right total score & $0.224^{*}$ & 0.024 \\
Y balance test left anterior & $0.209^{*}$ & 0.036 \\
Y balance test left posterolateral & $0.186^{*}$ & 0.062 \\
Y balance test left posteromedial & $0.211^{*}$ & 0.034 \\
Y balance test left total score & $0.228^{*}$ & 0.022 \\
Agility test & $-0.292^{*}$ & 0.038 \\
Vertical jump test & 0.161 & 0.260
\end{tabular}

*Significant correlation values.

Table 5. Functional movement screen scores of handball athletes $(n=50)$

\begin{tabular}{lr}
\hline Variable & Mean \pm SD \\
\hline Deep squat & $1.57 \pm 0.78$ \\
Hurdle step left & $1.94 \pm 0.42$ \\
Hurdle step right & $1.98 \pm 0.67$ \\
In line lunge left & $2.15 \pm 0.57$ \\
In line lunge right & $2.13 \pm 0.63$ \\
Shoulder mobility left & $2.37 \pm 0.84$ \\
Shoulder mobility right & $2.01 \pm 1.27$ \\
Active straight leg raise left & $2.33 \pm 0.73$ \\
Active straight leg raise right & $2.27 \pm 0.80$ \\
Trunk stability push-up & $1.78 \pm 0.72$ \\
Rotary stability left & $1.90 \pm 0.45$ \\
Rotary stability right & $1.92 \pm 0.44$ \\
Total score & $12.86 \pm 2.57$ \\
\hline
\end{tabular}

SD, standard deviation. 
are shown in Table 5.

In addition, the mean vertical jump test score was $40.73 \pm 9.78$ $\mathrm{cm}$. The mean time to complete the Illinois Agility Test was $17.82 \pm 1.15 \mathrm{sec}$.

\section{DISCUSSION}

In the present study, the FMS scores of the healthy handball athletes and their injury risks and functional disabilities were investigated. We found that the mean FMS scores of the handball athletes were below 14 points, indicating the risky border for possible injuries (Bushman et al., 2016). In addition, the rate of asymmetry was also high (68.62\%). Every sport's movements and risk of injury differs, but every functional activity exceeding the limit requires qualification in the optimum standard. Therefore, the FMS scores must be above the threshold value for each sport and athlete. The FMS scores were investigated in different studies including field sports events in Wales (Fox et al., 2014), nine different sports (Warren et al., 2015), runners (Hotta et al., 2015), athlete college students (Engquist et al., 2015; Sprague et al., 2014) cricket athletes (Martin et al., 2017), rugby players (Tee et al., 2016) and ice hockey players (Rowan et al., 2015). Our study results were compared with those of other sports, as the FMS evaluation system has not been used in the handball players in the literature, yet. In previous studies, the total scores were higher than our study, except for two studies.

In addition, our deep squat test results were below the acceptable values. Previous knee injuries of athletes were one of the factors which adversely affected the success of this test. Also, test scores were lower in an athlete who was unable to perform knee flexion due to pain or limited range of motion. However, the flexibility work usually limited to the hamstrings during training makes the athletes more disadvantaged in terms of flexibility of quadriceps and gastrosoleus muscle groups.

When jumping or shooting in a handball game, a lower extremity is in the air and stability is critical for the lower limb in the ground. The hurdle step test assesses the ability of these movements. In our study, we found that the athletes were at a sufficient level for this test.

Based on the characteristics of the handball sport, the body gains a rotational pattern during the unilateral movement, and the athlete must be able to maintain the stability. In our study, we observed that the athletes were at a sufficient level for this test. In our study, the athlete's shoulder mobility test score was below the accepted values, and the rate of asymmetry was high. The majori- ty of the athletes (86\%) used the right upper extremity dominantly. The extremity used was exposed to injuries, leading to low FMS scores. The shoulder mobility test score should be high in shoulder primary sports, although past injuries, inadequate treatments, or incorrect training reduce this score.

Furthermore, the results obtained from active leg raise test were acceptable, suggesting that working on the hamstring flexibility was adequately included in the training.

Trunk stability requires push-up, core stability, and triceps muscle strength. The results of our study show that the athletes were at a low level for this evaluation. This indicates that the athletes are inadequate for this parameter and are more vulnerable to possible injuries.

In the present study, our rotation stability test results were within the acceptable values with low asymmetry rates. In a previous study, the number of injuries was found to be 3.1 per 1,000 training hours and 40.7 per 1,000 hours of match (Wedderkopp et al., 1997), indicating low results, compared to our study results. However, in the study of Bere et al. (2015), the number of injuries was reported as 104.5 per 1,000 hr of match, which is similar to our results. In our study, the number of injuries to athletes was also found to be 115.81 per 1,000 hr of match and 9.93 per 1,000 training hours.

In a previous study, a relationship between the $\mathrm{Y}$ balance test results and FMS scores was reported (de la Motte et al., 2016). The result is also consistent with our study results. Functional movement is influenced by many parameters. One of these is balance and coordination ability. The FMS subparameters (i.e., deep squat, hurdle step, and in line lunge) directly or indirectly affect the balance, indicating that the FMS score is related to the Y balance score (Cook et al., 2006a).

In addition, agility is an important skill in handball sport as well as in many sports. There are several studies which report the reaction time, which can be regarded as the ability to respond to sudden changes, is also related to the agility test results (Homoud, 2015). Therefore, a low FMS score can also affect sports performance. Amiri-Khorasani et al. (2010) applied the Illinois Agility Test to soccer players and they found the mean score to be 14.90 sec while Hachana et al. (2013) in a total of 105 athletes (football, rugby and handball) found the mean score to be 16,30 sec. These results show that handball athletes in Turkey are open to development in terms of athletic parameters.

We also found a statistically significant negative correlation between the FMS scores and Illinois Agility Test scores. In our study, the Illinois Agility Test of an athlete was low if the FMS 
scores were low, as well. This result can be explained by the fact that the agility test requires a sudden acceleration and sudden change of direction and that there is a kinetic chain, painless, and functional movement that works properly for these movements.

On the other hand, there is no correlation found between the FMS scores and vertical jump test results. In a study, Parchman and McBride (2011) reported no correlation between the FMS scores and vertical jump test. As the vertical jumping movement has a static nature, it can explain that this score is not affected by the functional movement. In their study, Vila et al. (2012) also reported a mean $42-\mathrm{cm}$ vertical jump test score in a total of 130 elite handball athletes. These results are consistent with our study results.

In conclusion, handball athletes must first eliminate functional deficiencies, since handball is a high-risk sport and requires many athletic qualifications. We believe that coaches and athletes should be trained on FMS-corrective approaches which are included in their training programs. The addition of the FMS approach to preseasonal scans of the athletes is critical to reduce the injury risk, to manage athletes' health approaches, and to enhance their performance. By integrating the FMS system, it is also possible to reduce the moral losses due to injuries. Although our study is valuable in handball sport and pioneering studies using the FMS approach, long-term results of the corrective approach proposals given to the participants and coaches should be obtained in the near future.

Nonetheless, there are some limitations to this study. First, further large-scale, comparative studies including different sports branches are required to confirm these findings. Second, due to the lack of studies in the literature showing the FMS scores of handball athletes, we were only able to compare our results with those of sports with different branches. Another limitation of our study is that we were unable to perform a cost-efficacy analysis. Further studies, therefore, are needed to confirm these findings.

\section{CONFLICT OF INTEREST}

No potential conflict of interest relevant to this article was reported.

\section{REFERENCES}

Amiri-Khorasani M, Sahebozamani M, Tabrizi KG, Yusof AB. Acute effect of different stretching methods on Illinois agility test in soccer players. J Strength Cond Res 2010;24:2698-2704.
Bencke J, Curtis D, Krogshede C, Jensen LK, Bandholm T, Zebis MK. Biomechanical evaluation of the side-cutting manoeuvre associated with ACL injury in young female handball players. Knee Surg Sports Traumatol Arthrosc 2013;21:1876-1881.

Bere T, Alonso JM, Wangensteen A, Bakken A, Eirale C, Dijkstra HP, Ahmed H, Bahr R, Popovic N. Injury and illness surveillance during the 24th Men's Handball World Championship 2015 in Qatar. Br J Sports Med 2015;49:1151-1156.

Bushman TT, Grier TL, Canham-Chervak M, Anderson MK, North WJ, Jones $\mathrm{BH}$. The functional movement screen and injury risk: association and predictive value in active men. Am J Sports Med 2016;44:297304.

Carlock JM, Smith SL, Hartman MJ, Morris RT, Ciroslan DA, Pierce KC, Newton RU, Harman EA, Sands WA, Stone MH. The relationship between vertical jump power estimates and weightlifting ability: a fieldtest approach. J Strength Cond Res 2004;18:534-539.

Chorba RS, Chorba DJ, Bouillon LE, Overmyer CA, Landis JA. Use of a functional movement screening tool to determine injury risk in female collegiate athletes. N Am J Sports Phys Ther 2010;5:47-54.

Cook G, Burton L, Hoogenboom B. Pre-participation screening: the use of fundamental movements as an assessment of function - part 1. N Am J Sports Phys Ther 2006a;1:62-72.

Cook G, Burton L, Hoogenboom B. Pre-participation screening: the use of fundamental movements as an assessment of function - part 2. N Am J Sports Phys Ther 2006b;1:132-139.

de la Motte SJ, Lisman P, Sabatino M, Beutler AI, O'Connor FG, Deuster PA. The relationship between functional movement, balance deficits, and previous injury history in deploying marine warfighters. J Strength Cond Res 2016;30:1619-1625.

Engquist KD, Smith CA, Chimera NJ, Warren M. Performance comparison of student-athletes and general college students on the functional movement screen and the $Y$ balance test. J Strength Cond Res 2015;29: 2296-2303.

Fox D, O'Malley E, Blake C. Normative data for the Functional Movement Screen in male Gaelic field sports. Phys Ther Sport 2014;15:194199.

Garrison M, Westrick R, Johnson MR, Benenson J. Association between the functional movement screen and injury development in college athletes. Int J Sports Phys Ther 2015;10:21-28.

Hachana Y, Chaabène H, Nabli MA, Attia A, Moualhi J, Farhat N, Elloumi M. Test-retest reliability, criterion-related validity, and minimal detectable change of the Illinois agility test in male team sport athletes. J Strength Cond Res 2013;27:2752-2759.

Homoud MN. Relationships between Illinois Agility Test and reaction time in male athletes. Swed J Sci Re 2015;2:28-33. 
Hotta T, Nishiguchi S, Fukutani N, Tashiro Y, Adachi D, Morino S, Shirooka H, Nozaki Y, Hirata H, Yamaguchi M, Aoyama T. Functional Movement Screen for predicting running injuries in 18- to 24-year-old competitive male runners. J Strength Cond Res 2015;29:2808-2815.

Karcher C, Buchheit M. On-court demands of elite handball, with special reference to playing positions. Sports Med 2014;44:797-814.

Kiesel K, Plisky PJ, Voight ML. Can serious injury in professional football be predicted by a preseason functional movement screen? N Am J Sports Phys Ther 2007;2:147-158.

Martin C, Olivier B, Benjamin N. The functional movement screen in the prediction of injury in adolescent cricket pace bowlers: an observational study. J Sport Rehabil 2017;26:386-395.

Narducci E, Waltz A, Gorski K, Leppla L, Donaldson M. The clinical utility of functional performance tests within one-year post-acl reconstruction: a systematic review. Int J Sports Phys Ther 2011;6:333-342.

Parchmann CJ, McBride JM. Relationship between functional movement screen and athletic performance. J Strength Cond Res 2011;25:33783384.

Plisky PJ, Gorman PP, Butler RJ, Kiesel KB, Underwood FB, Elkins B. The reliability of an instrumented device for measuring components of the star excursion balance test. N Am J Sports Phys Ther 2009;4:92-99.

Rowan CP, Kuropkat C, Gumieniak RJ, Gledhill N, Jamnik VK. Integration of the functional movement screen into the National Hockey League Combine. J Strength Cond Res 2015;29:1163-1171.

Shojaedin SS, Letafatkar A, Hadadnezhad M, Dehkhoda MR. Relationship between functional movement screening score and history of in- jury and identifying the predictive value of the FMS for injury. Int J Inj Contr Saf Promot 2014;21:355-360.

Singh B, Kumar A, Ranga M. Comparison of vertical jump performance of male hockey and football players. J Exerc Sci Physiother 2016;12:8186.

Sprague PA, Mokha GM, Gatens DR. Changes in functional movement screen scores over a season in collegiate soccer and volleyball athletes. J Strength Cond Res 2014;28:3155-3163.

Tee JC, Klingbiel JF, Collins R, Lambert MI, Coopoo Y. Preseason functional movement screen component tests predict severe contact injuries in professional rugby union players. J Strength Cond Res 2016;30: 3194-3203.

Vila H, Manchado C, Rodriguez N, Abraldes JA, Alcaraz PE, Ferragut C. Anthropometric profile, vertical jump, and throwing velocity in elite female handball players by playing positions. J Strength Cond Res 2012;26:2146-2155.

Warren M, Smith CA, Chimera NJ. Association of the Functional Movement Screen with injuries in division I athletes. J Sport Rehabil 2015; 24:163-170

Wedderkopp N, Kaltoft M, Lundgaard B, Rosendahl M, Froberg K. Injuries in young female players in European team handball. Scand J Med Sci Sports 1997;7:342-347.

Wischmeyer A, Hoang H, Gutierrez A, Hernandez B, Roger N. Relationship between $Y$ balance test scores and injury risk among crossfit participants. J Orthop Sports Phys Ther 2016;46:A206-207. 